\title{
LPS Exposure in Early Life Protects Against Mucus Hypersecretion in Ovalbumin- Induced Asthma by Down-Regulation of the IL-13 and JAK-STAT6 Pathways
}

\author{
Fengxia Ding ${ }^{a}$ Bo Liu ${ }^{b}$ Wenjing Zou ${ }^{a}$ Daiyin Tiana Qubei Lia Jihong Daia \\ Zhengxiu Luo ${ }^{\text {a }}$ Zhou Fu
}

\begin{abstract}
aDepartment of Pediatric respiratory medicine, Children's Hospital of Chongqing Medical University, Ministry of Education Key Laboratory of Child Development and Disorder, Chongqing, China International Science and Technology Cooperation base of Child development and Critical Disorders. Chongqing Key Laboratory of Child Infection and Immunity, 'bepartment of Urology, Children's Hospital of Chongqing Medical University, Ministry of Education Key Laboratory of Child Development and Disorder, Chongqing, China
\end{abstract}

\section{Key Words}

Lps • Asthma • Mucus hypersecretion • IL-13 • JAK-STAT6

\begin{abstract}
Background/Aims: Previous studies have shown that lipopolysaccharide (LPS) exposure may have a protective effect on asthma by reducing airway hyper-responsiveness, airway inflammation and serum IgE levels. However, there are few studies investigating the effect of LPS on mucous secretion in asthma. In this study, we evaluate the relationship between LPS pre-treatment in infant mice and airway mucus hypersecretion in an OVA (ovalbumin)induced asthma model, and further explore the mechanisms behind this effect. Methods: Mice were pre-treated with LPS by intranasal instillation (i.n.) from the $3^{\text {rd }}$ day of life for 10 consecutive days before the OVA-induced asthma model was established. In order to detect mucus secretion, periodic acid-Schiff (PAS) staining was carried out, and the expression of Muc5ac was detected. The IL-13 levels in Bronchoalveolar lavage fluid (BALF) and lung tissue were also detected. In vitro, the expression of Muc5ac mRNA and protein was quantified in IL-13-stimulated 16HBE cells with or without LPS pre-treatment. In addition, proteins in the JAK2/STAT6 pathway, transcription factors (forkhead box transcription factor A2 (FOXA2), activation protein-1(AP-1), NF-kB), and the levels of reactive oxygen species (ROS) were also measured in vivo and in vitro. Results: LPS pre-treatment reduced mucus secretion, as demonstrated by decreased PAS staining and muc5ac expression. Further exploration of the underlying mechanisms of this phenomenon revealed that LPS pre-treatment decreased the production of IL-13, IL-13 induced ROS synthesis was reduced, and the JAK2/STAT6 pathway
\end{abstract}


was inhibited. Decreased stat6 increased transcription factor FOXA2, and the relatively increased FOXA2 further decreased the level of Muc5ac and mucous hypersecretion in OVAinduced asthma. Conclusions: LPS pre-treatment ameliorated mucus hypersecretion in an OVA-induced asthma model by inhibition of IL-13 production and by further inhibiting the JAK2/STAT6 pathway and ROS activity, and up-regulating expression of FOXA2.

\section{The Author(s)}

Published by S. Karger AG, Basel

\section{Introduction}

Asthma is a complex inflammatory disease in the lungs characterized by infiltration of the bronchial mucosa by mast cells, lymphocytes and eosinophils, goblet cell hyperplasia, together with activation of $\mathrm{T}$ cells. Mucus hypersecretion is an important pathological feature of bronchial asthma, which has become an independent risk factor for the prognosis of asthma. Therefore, it is important to develop drugs that inhibit mucus hypersecretion in susceptible patients. Before addressing these issues, more information is required on mucus physiology and pathophysiology. The mucin family includes Muc2, Muc4, Muc5ac and Muc5b, among others. Among these, Muc5ac is mainly expressed in airway epithelium goblet cells, thus Muc5ac is the most important representative of mucus in asthma [1].

Asthma is associated with Th2 polarization, which produces interleukin-4 (IL-4), IL-5, IL-9 and IL-13 [2]. Among those, IL-13 is now thought to be especially critical. In animal models of allergic asthma, the administration of IL-13 markedly increased mucous hypersecretion [3]. However, after the application of IL-13 monoclonal antibodies or the knockout of IL-13 in asthmatic mice, goblet cell metaplasia in the airways significantly weakened or disappeared [4,5].

Endotoxin (lipopolysaccharide, LPS), a major component of the outer cell wall of Gram negative bacteria, is ubiquitous in the environment. Epidemiological evidence suggests that exposure to LPS in the environment can protect against asthma by reducing airway hyperresponsiveness, airway inflammation and serum IgE levels through down-regulation of the Th2 response [6-8]. In addition, our previous study has shown that LPS exposure downregulates the response of Th2 cells, and decreases the levels of cytokines released by Th2 cells. This was especially true for IL-13, which is an important factor to induce mucus hypersecretion (unpublished data). Thus, we investigated whether LPS pre-treatment could decrease mucus hypersecretion and sought to understand the mechanisms underlying this effect.

\section{Materials and Methods}

\section{Experimental Animals}

BALB/c mice were kept in a specific pathogen free condition and received sterile OVA-free food and water. The mice were maintained on a 12 hour light/dark cycle, under constant room temperature $\left(24^{\circ} \mathrm{C}\right)$ and relative humidity (40-80\%). The experimental protocols shown in this study were approved by the Institutional Animal Care and Research Advisory Committee at Chongqing Medical University. The use of animals in these experiments was in accordance with the guidelines issued by the Chinese Council on Animal Care.

\section{Neonatal LPS pre-treatment and OVA sensitization and challenge}

In a pilot experiment, different doses of LPS were administered at different times to find the optimal dose and "time window" for LPS protection in the OVA-induced asthma model. From the $3^{\text {rd }}$ day of life, mice were exposed to $1 \mu \mathrm{g}$ LPS (Escherichia coli serotype 0111:B4; Sigma-Aldrich) dissolved in $10 \mu \mathrm{l}$ sterile phosphate buffer (PBS) by intranasal instillation (i.n.) for consecutive 10 days. The control animals received sterile PBS i.n. After LPS exposure was successfully established, the OVA-induced mouse model of asthma was established in the first 6 weeks of life according to previous published methods [9]. 


\section{Cellular Physiology Cell Physiol Biochem 2018;46:1263-1274 \begin{tabular}{l|l} 
and Biochemistry Published online: April 20, 2018 & $\begin{array}{l}\text { (c) } 2018 \text { The Author(s). Published by S. Karger AG, Basel } \\
\text { www.karger.com/cpb }\end{array}$
\end{tabular}}

Ding et al.: LPS Protect Against Mucus Hypersecretion

Airway hyper-responsiveness (AHR)

AHR was measured 24 hours after ovalbumin challenge by measuring the lung resistance (LR). Animals were anaesthetized with pentobarbital (30 mg/ $\mathrm{kg}$ ip) and connected via a tracheostomy tube to a computer-controlled small animal ventilator (flexiVent, Scireq). Mice were then challenged with acetyl- $\beta$ methacholine (Sigma-Aldrich, Saint Louis, MO, USA), at increasing doses: 0, 3.125, 6.25, 12.5, 25 and 50mg/ $\mathrm{mL}$.

\section{Bronchoalveolar lavage and cell counting}

Within $24 \mathrm{~h}$ after the final challenge, mice were sacrificed and the trachea was cannulated. Bronchoalveolar lavage fluid (BALF) was obtained by flushing the lungs three times with $1.5 \mathrm{~mL}$ PBS. Total BALF cell numbers, eosinophils and neutrophils were counted after Wright-Giemsa staining, based on standard morphologic and staining characteristics of 200 cells per sample. The percentage and absolute numbers of each cell type were calculated. The supernatant was stored at $-80^{\circ} \mathrm{C}$.

\section{BALF cytokine measurements and serum IgE}

IL-13 (NeoBioscience, Shenzhen, China) concentrations in BALF were measured with commercial enzyme-linked immunosorbent assay (ELISA) kits according to the manufacturer's instructions. Serum was separated to assess IgE levels using a murine IgE ELISA kit (NeoBioscience, Shenzhen, China).

\section{Histological analysis}

Lung tissues from the mice were harvested and embedded in paraffin. The paraffin blocks were serially sectioned at $4 \mu \mathrm{m}$ thickness and stained with hematoxylin-eosin (H\&E) and then stained with periodic acid-Schiff (PAS) and Alcian blue (AB). These stains allow the identification of mucus glycoconjugates and mucus-producing goblet cells in accordance with standard protocols. Immunohistochemical (IHC) analysis was performed with antibodies specific to Muc5ac (Abcam, USA). Briefly, after IHC staining, cells stained light yellow to brown were recorded as positive for immunostaining. Images were captured under a Nikon Eclipse E200 microscope connected to a Nikon Coolpix 995 camera (Nikon, Tokyo, Japan).

\section{Normal human bronchial epithelial cell culture}

The human bronchial epithelial cell line-16 (16HBE) cells were cultured in RPMI-1640 medium $(10 \%$ fetal bovine serum and $1 \%$ weight per volume penicillin/streptomycin). Cells were maintained in a humidified atmosphere of $5 \% \mathrm{CO}_{2}$ in air at $37^{\circ} \mathrm{C}$.

\section{Treatment of $16 \mathrm{HBE}$ cells}

The 16HBE cells were serum starved for $24 \mathrm{~h}$ to maintain a low basal level of Muc5ac production. Three days after the LPS pre-treatment $(10 \mathrm{ng} / \mathrm{mL})$, the cells were further treated with or without IL-13 (10 $\mathrm{ng} / \mathrm{mL}$ ) for 12 hours [5]. The negative control group was incubated with PBS only. The cells were divided into four groups: the LPS pre-treatment and IL-13 stimulated (LPS/IL-13); the PBS pre-treatment and IL-13 stimulated (PBS/IL-13); the LPS pre-treatment and PBS stimulated (LPS/PBS); the PBS pre-treatment and PBS stimulated (Control). At the end of stimulation, the cells were collected for further evaluations.

\section{Reactive oxygen species (ROS) assay}

For reactive oxygen species generation, the harvested lung homogenates were incubated with $100 \mu \mathrm{M}$ 6-carboxy-2',7'-dichlorofluorescin diacetate (DCFH-DA) for $30 \mathrm{~min}$ at $37^{\circ} \mathrm{C}$. DCFH-DA forms a fluorescent product, DCF (dichlorofluorescein) upon oxidation with ROS. Fluorescence caused by DCF in each well was measured and recorded for $30 \mathrm{~min}$ at $485 \mathrm{~nm}$ (excitation) and $530 \mathrm{~nm}$ (emission) according to the method of Wang and Joseph [10]. The background fluorescence caused by the buffer and by DCF were subtracted from the total fluorescence in each well. Fluorescence intensity was expressed as ROS generation (\% control).

\section{Immunofluorescence}

16HBE Cells were fixed with formaldehyde before overnight incubation at $4^{\circ} \mathrm{C}$ with the primary antibody (anti-Muc5ac) diluted 1/100, then the cell were stained with secondary antibody (red). And after washing with PBS, the cell nuclei were stained with DAPI (Blue). Cells were examined using fluorescence confocal microscopy. 


\section{Cellular Physiology Cell Physiol Biochem 2018;46:1263-1274 \begin{tabular}{c|c|c|} 
DOI: 10.1159/000489109 & O 2018 The Author(s). Published by S. Karger AG, Basel \\
www.karger.com/cpb
\end{tabular} \\ Ding et al.: LPS Protect Against Mucus Hypersecretion}

Flow cytometric analysis

The lungs were minced and incubated for $20 \mathrm{~min}$ at $37^{\circ} \mathrm{C}$ in $1 \mathrm{~mL}$ of sterile PBS containing $0.2 \%$ collagenase I (Sigma-Aldrich). Single pulmonary cell suspensions were obtained by forcing tissue through a $70 \mu \mathrm{m}$ cell filter (Becton, Dickinson and Company, Franklin Lakes, NJ, USA). Erythrocytes were lysed, and the remaining cells were resuspended in RPMI 1640 medium containing $10 \%$ fetal bovine serum. A single-cell suspension from the lung $\left(2 \times 10^{6}\right.$ cells $\left./ \mathrm{mL}\right)$ was incubated for $4-6 \mathrm{~h}$ at $37^{\circ} \mathrm{C}$ and $5 \% \mathrm{CO}^{2}$ in $1 \mathrm{~mL}$ medium containing phorbol 12-myristate 13-acetate (PMA) $(50 \mathrm{ng} / \mathrm{mL}$; Sigma-Aldrich), ionomycin $(500 \mathrm{ng} / \mathrm{mL}$; Sigma-Aldrich) and GolgiPlug-containing brefeldin A (Becton, Dickinson and Company). The cells were then blocked with rat serum and subsequently stained for surface-associated CD4 (anti-CD4-FITC; Pharmingen of Becton, Dickinson and Company), or CD3 (anti-CD3-PerCP-Cy5.5; Pharmingen). To detect the IL-13 in $\mathrm{CD} 4^{+} \mathrm{T}$ cells in the lungs, the cells were stained for intracellular IL-13 (anti-IL-13-PE-Cy7; Pharmingen), and detected by flow cytometry (FACS Canto; Becton, Dickinson and Company). The data were analyzed with Cell Quest software (Becton, Dickinson and Company).

RNA extraction, reverse transcription and quantitative PCR

The total RNA from mice lung tissues was purified, and cDNA synthesis was performed with a Prime Script RTReagent Kit (Takara, Otsu, Japan). Real-time quantitative PCR (q-PCR) was performed using standard techniques. In each sample, GAPDH was used as an internal control. The primer sequences of IL13 mRNA were:5'-CCTGGCTCTTGCTTGCCTT-3' (forward)

5'-GGTCTTGTGTGATGTTGCTCA-3' (reverse).

Muc5ac primer sequences were:

5'-CAGCCGAGAGGAGGGTTTGATCT-3' (forward)

5'-AGTCTCTCTCCGCTCCTCTCAAT-3' (reverse).

FOXA2 primer sequences were:

5'-CCCCTGAGTTGGCGGTGGT-3' (forward)

5'-TTGCTCACGGAAGAGTAGCC-3' (reverse).

AP-1 primer sequences were:

5'-AAACGACCTTCTATGACGATGC-3' (forward)

5-CCGTTGCTGGACTGGATTAT-3' (reverse).

NF-KB primer sequences were:

5'-CAGTGAAGACCACCTCTCTCAGG-3' (forward)

5'-AGAGTTAGCAGTGAGGCACCA-3' (reverse).

p-STAT6 primer sequences were:

5'-GCATCTTGCCGCACATCA-3' (forward)

5'-GGTTCGCAGGACTTCATC -3' (reverse).

GAPDH primer sequences were:

5'-AGCAATGCCTCCTGCACCACCAAC-3' (forward)

5'-CCGGAGGGGCCATCCACAGTCT-3' (reverse).

The 16HBE cells were washed twice with PBS and $1 \mathrm{~mL}$ of Trizol was added for RNA extraction. The RNA pellet was then dissolved in RNase-free water and stored at $-80^{\circ} \mathrm{C}$ until use. The primer sequences ofhMuc5ac were:

5'-TCAACGGAGACTGCGAGTACAC-3' (forward)

5'-TCTTGATGGCCTTGGAGCA-3' (reverse).

hp-STAT6 primer sequences were:

5'-AGACCAGGACCTACGGACATACC-3' (forward)

5'-CTCTGCGAAGATACAGCCAACAC -3' (reverse).

hFOXA2 primer sequences were:

5'-CGTCCGACTGGAGCAGCTACTA-3' (forward) and

5'-ATGTACGTGTTCATGCCGTTCA-3' (reverse).

hAP-1 primer sequences were:

5'-TTCAAATAATCAACTTT-3' (forward)

5'-TAAGTTTATTAGTTGAA-3' (reverse).

hNF- $\mathrm{kB}$ primer sequences were:

5'-CAGAGAGGATTTCGTTTCCGTTATG-3' (forward) 


\title{
Cellular Physiology Cell Physiol Biochem 2018;46:1263-1274 \begin{tabular}{ll|l} 
and Biochemistry & $\begin{array}{l}\text { DOI: 10.1159/000489109 } \\
\text { Published online: April 20, } 2018\end{array}$ & $\begin{array}{l}\text { () 2018 The Author(s). Published by S. Karger AG, Basel } \\
\text { www.karger.com/cpb }\end{array}$ \\
\hline
\end{tabular} \\ Ding et al.: LPS Protect Against Mucus Hypersecretion
}

\author{
5'-GCAGATTTTGACCTGAGGGTAAGAC-3' (reverse). \\ hGAPDH primer sequences were: \\ 5'-ACTCGTGCTGGGTGGTGGTG-3' (forward) \\ 5'-CTGCAGGCACGTCATGAA TCT-3' (reverse).
}

\section{Western blot}

The total proteins from mice lung tissues and 16HBE cells were isolated, and the protein concentrations were determined using a bicinchoninic acid assay. The proteins from whole-cell lysates were used for Western blot using standard techniques as reported [11]. Anti-Muc5ac (Abcam, USA), anti-JAK2, anti-p-JAK2, antiSTAT6, anti-p-STAT6 (1:2000) (Cell Signaling Technology, USA) antibodies were used. Densitometry of bands from Western blots was done by ImageJ2x 2.1.4.7 (Wayne Rasband, National Institutes of Health, USA), and the density of the Muc5ac, JAK2, p-JAK2, STAT6, p-STAT6 proteins relative to $\beta$-actin was measured.

\section{Statistical analyses}

The data are expressed as the mean with the standard error of the mean (SEM). All data were analyzed using SPSS 17.0 software. The statistical analyses of LR were performed with two-way ANOVAs and for WB analysis with one-way ANOVAs and the Student's t-test. Differences with P-values less than 0.05 were considered to be statistically significant.

\section{Results}

\section{Effect of LPS pre-treatment on an OVA-induced asthma model}

The OVA-induced mouse model of asthma was established in the first 6 weeks of life (Fig. 1). To identify the effect of LPS pre-treatment on lung function in an OVA-induced asthma model, AHR of LR was detected by invasive lung function testing. Our OVA-induced asthma model (PBS/OVA) showed an increased AHR compared with control mice challenged with PBS, and LPS pre-treatment (LPS/OVA) ameliorates the AHR compared with PBS/OVA mice (Fig. 2A, $\mathrm{P}<0.05$ ). Histological evaluation of lung tissue in the PBS/OVA group revealed higher levels of peribronchial inflammation compared with the control group. However, peribronchial inflammation was significantly reduced in LPS/OVA mice compared with PBS/ OVA mice (Fig. $2 \mathrm{~B}, \mathrm{P}<0.05$ ). Besides, as compared with the control group, mice in the PBS/ OVA group showed a significant increase in serum IgE levels and total cell numbers, as well as eosinophils and neutrophils in BALF. However, LPS pre-treatment (LPS/OVA) significantly reduced all these changes compared with the PBS/OVA group (Fig. $2 \mathrm{C}$ and $2 \mathrm{D}, \mathrm{P}<0.05$ ).

\section{LPS pre-treatment ameliorates mucus secretion}

To determine if LPS pre-treatment could exert protective effects on OVA-induced mucus secretion, lung histologic sections were harvested $24 \mathrm{~h}$ after the last provocation. The control group showed little mucus production, whereas OVA - chall en ge d mice (PBS/OVA) exhibited gobletcell hyperplasia and mucus hypersecretion within the airway epithelia. However, LPS pre-treatment significantly reduced O V A - i n d u c e d mucus secretion in LPS/OVA mice

\begin{tabular}{|c|c|c|c|c|c|c|c|}
\hline \multirow[b]{2}{*}{ Birth 0 day } & \multicolumn{2}{|c|}{ 10days } & \multirow[b]{2}{*}{$\underset{42 \mathrm{~d}}{\downarrow}$} & \multirow[b]{2}{*}{$\underset{56 \mathrm{~d}}{\downarrow}$} & \multirow[b]{2}{*}{$\underset{72 d}{\square}$} & \multirow[b]{2}{*}{$81 d$} & \multirow[b]{2}{*}{$\underset{82 \mathrm{~d}}{\downarrow}$} \\
\hline & $\begin{array}{c}\downarrow \\
3 \mathrm{~d}\end{array}$ & $\underset{12 \mathrm{~d}}{\downarrow}$ & & & & & \\
\hline Control & & & PBS sensitization & PBS sensitization & & PBS challenge & sacrificed \\
\hline PBS/OVA & & & OVAsensitization & OVAsensitization & & OVA challenge & \\
\hline LPSIOVA & & & OVAsensitization & OVAsensitization & & OVAchallenge & \\
\hline LPSIPBS & & & PBS sensitization & PBS sensitization & & PBS challenge & \\
\hline
\end{tabular}

Fig. 1. Experimental design and protocols employed in this study. From the 3rd day of life BALB/c mice were exposed to $1 \mu \mathrm{g}$ LPS i.n. dissolved in $10 \mu \mathrm{l} \mathrm{PBS}$ or PBS alone for 10 days consecutively, and were sensitized and challenged with or without OVA from the $6^{\text {th }}$ week of life (Grouping: Control, PBS/OVA, LPS/OVA, LPS/PBS group). At day 82, all mice were sacrificed. $\mathrm{n}=6-8$ mice per group. 
Fig. 2. Effect of LPS pre-treatment on an OVA-induced asthma model. LPS pre-treatment induced a decrease in AHR, inflammatory peribronchial neutrophils, and serum IgE levels as well as lower total cell count, eosinophils and neutrophils in BALF (Grouping: Control, PBS/OVA, LPS/OVA, LPS/PBS) ( $n=6-8$ /group). A. Invasive lung function: AHR in reaction to increased doses of methacholine was measured $24 \mathrm{~h}$ after the final challenge. Data are shown as the mean \pm SEM of LR from experimental and control groups of mice. ${ }^{*} \mathrm{P}<0.05,{ }^{* *} \mathrm{P}<0.01$, ${ }^{* * *} \mathrm{P}<0.001$ as compared with the PBS/OVA group. B. HE staining: representative lung tissue sections of each group were stained with hematoxylin and eosin (HE) $24 \mathrm{~h}$ after the final challenge. Magnification: $\times 200$ and $\times 400$. C. Serum IgE: serum IgE was measured by ELISA. ${ }^{*} \mathrm{P}<0.05,{ }^{* *} \mathrm{P}<0.01,{ }^{* * *} \mathrm{P}<0.001$ as compared with the PBS/OVA group. D. Total cell

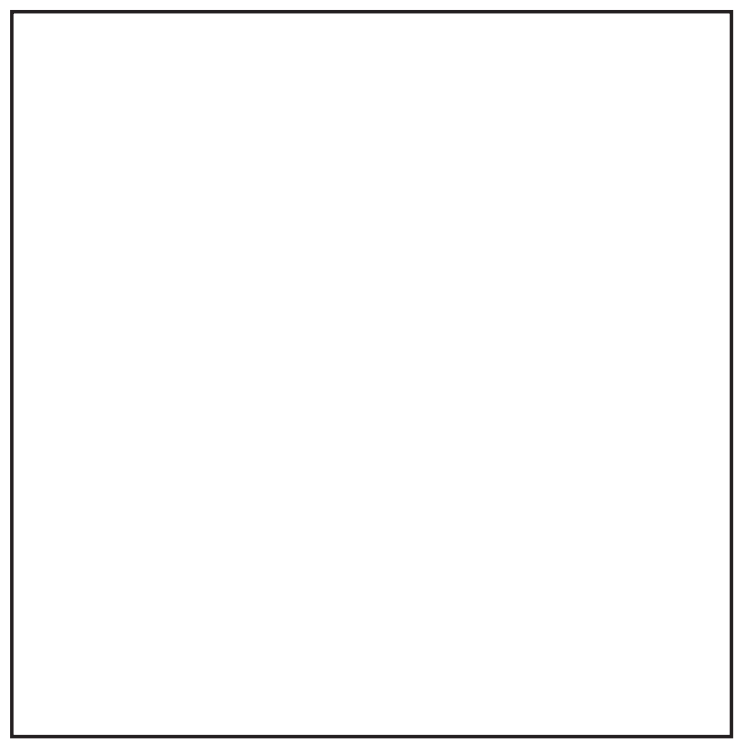
count (a), neutrophils (b), and eosinophils (c) were counted from BALF collected $24 \mathrm{~h}$ after the final challenge. Data are means $\pm \mathrm{SEM},{ }^{*} \mathrm{P}<0.05,{ }^{* *} \mathrm{P}<0.01,{ }^{* * *} \mathrm{P}$ $<0.001$ as compared with the PBS/OVA group.

Fig. 3. LPS pre-treatment decreases mucous secretion in an OVA-induced asthma model. PAS-positive intracellular mucin granules populated the epithelium, magnification: $\times 200$ and $\times 400$ (A). Muc5ac protein expression level (B). Quantification of $\mathrm{Mu}-$ c5ac protein expression level (C). Representative images of Muc5ac immunohistochemical staining in lung sections, magnification: $\times 400$ (D). q-PCR of Muc5ac mRNA (E). Data are means $\pm \mathrm{SEM},{ }^{*} \mathrm{P}<0.05$, ${ }^{* *} \mathrm{P}<0.01,{ }^{* * *} \mathrm{P}<0.001$ as compared with the PBS/ OVA group ( $\mathrm{n}=6-8 /$ group).

compared with PBS/OVA mice (Fig. 3A). As Muc5ac is a representative of airway goblet cell hyperplasia [1], we further measured the expression of Muc5ac. The results demonstrated that the

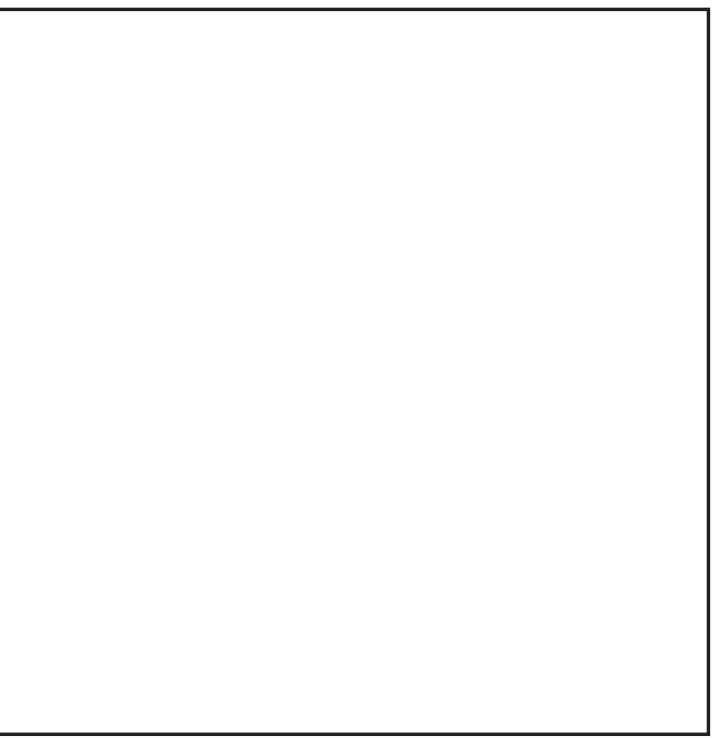
immunohistochemical staining of Muc5ac is

higher in OVA-induced asthma (PBS/OVA) compared with control mice, while it is decreased in LPS pre-treated mice (LPS/OVA) compared with PBS/OVA mice (Fig. 3D, P<0.05). In parallel, Muc5ac protein levels and Muc5ac mRNA is elevated in the PBS/OVA group compared with the control group, while LPS pretreatment significantly decreased Muc5ac protein expression and Muc5ac mRNA in the LPS/OVA group compared with the PBS/OVA group (Fig. 3B, 3C and 3E, $\mathrm{P}<0.05$ ).

\section{Decreased IL-13 levels in LPS pre-treated OVA-induced mice}

Since we found that mucus hypersecretion is decreased in LPS/OVA mice, we further studied the mechanisms underlying this finding. It has been reported that the Th2-related cytokine IL-13 was increased in asthma, which could significantly increase mucous hypersecretion [5]. Thus, we measured the IL-13 concentrations in our mouse model. Our results showed that IL-13 expression on $\mathrm{CD}^{+}{ }^{+}$T cells, IL-13 cytokines in BALF and IL-13 mRNA 
in lung tissue were all increased in the PBS/ OVA mice compared with the control mice, while they were significantly decreased in the LPS/ OVA mice compared with the PBS/OVA mice (Fig. 4, $\mathrm{P}<0.05$ ). Therefore, our study showed that LPS pretreatment can downregulate $\mathrm{IL}-13$ in our OVA-induced asthma model.

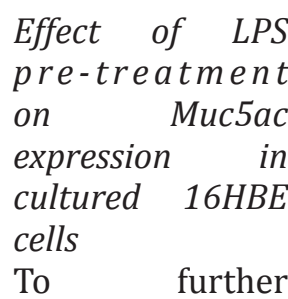
investigate the effect of decreased IL-13 on the regulation of Muc5ac, we measured the Muc5ac levels after IL-13 stimulation in $16 \mathrm{HBE}$ cells. In an in vitro experiment, IL-13 stimulated 16HBE cells induced increased Muc5ac immunofluorescence intensity, Muc5ac protein expression and Muc5ac mRNA in cells given PBS/ IL-13 compared with the control cells (Fig. 5, $\mathrm{P}<0.05)$. However, Muc5ac immunofluorescence intensity, Muc5ac protein expression and Muc5ac mRNA were decreased significantly in cells pre-treated with LPS (LPS/IL-13) compared with PBS/ IL-13 (Fig. 5, P<0.05). Therefore, we conclude that the decreased IL-13 following LPS pretreatment could be responsible for the Muc5ac expression in vivo and in vitro, which may therefore ameliorate mucus hypersecretion in asthma.

\section{Effect of LPS pre-treatment on p-JAK2, p-STAT6 and ROS generation in mice and $16 H B E$} cells

We further studied the specific mechanisms of how a decrease in IL-13 stimulated by LPS pre-treatment could result in decreased Muc5ac levels. The mechanism by which IL13 regulates mucin synthesis is complicated, including mitogen-activated protein kinase/
Fig. 4. IL-13 production is decreased in LPS pre-treated mice. IL-13 expression as measured by flow cytometry (FCM) (A). Cytokines of IL-13 production in BALF as measured by ELISA (B). Expression of IL13 mRNA as measured by q-PCR (C). ${ }^{*} \mathrm{P}<0.05$, ${ }^{* *} \mathrm{P}<0.01,{ }^{* * *} \mathrm{P}<0.001$ as compared with the PBS/OVA group ( $\mathrm{n}=6-8$ /group)

Fig. 5. Decreased Muc5ac expression in LPS/IL-13 cells compared with PBS/IL-13 cells. Grouping: LPS pre-treatment and IL13 stimulated (LPS/ IL-13); PBS pre-treatment and IL-13 stimulated (PBS/IL-13); LPS pre-treatment and PBS stimulated (LPS/PBS); PBS pretreatment and PBS stimulated (Control). Confocal microscopy of Muc5ac immunofluorescence, magnification: $\quad \times 400(\mathrm{~A})$. Western blot of $\mathrm{Mu}$ -
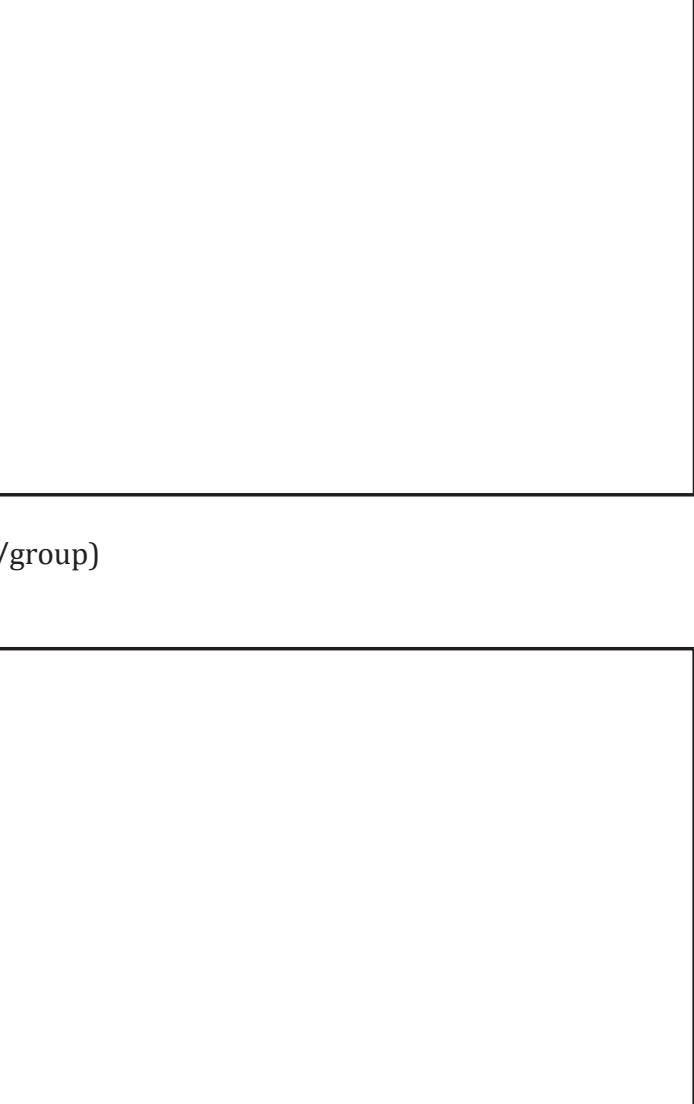

B
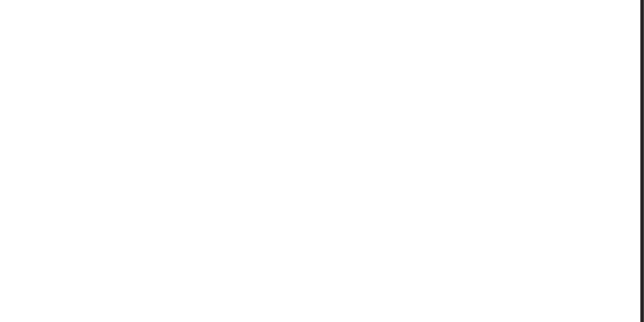

Quantification of Muc5ac protein levels(C). q-PCR of Muc5ac mRNA (D). Data are means $\pm \mathrm{SEM},{ }^{*} \mathrm{P}<0.05,{ }^{* *} \mathrm{P}<0.01,{ }^{* * *} \mathrm{P}<0.001$ as compared with the PBS/ IL-13 group, ( $n=6-8 /$ group). 


\section{Cellular Physiology Cell Physiol Biochem 2018;46:1263-1274

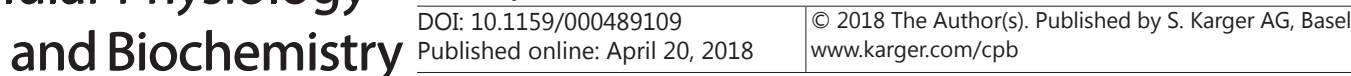

Fig. 6. Decreased expression of p-JAK2, p-STAT6 and reactive ROS, and increased FOXA2 mRNA in LPS pre-treated mice. Western blots of t-JAK2, $\mathrm{t}$ STAT6, p-JAK2 and p-STAT6 protein expression in lung tissues (A). Expression of p-STAT6 mRNA in lung tissues as measured by q-PCR (B). Reactive ROS in lung homogenate (C). Expression of FOXA2, AP-1 and NF- $\mathrm{KB}$ mRNA in lung tissues as measured by $\mathrm{q}-\mathrm{PCR}$ (D). Data are means $\pm \mathrm{SEM},{ }^{*} \mathrm{P}<0.05$, ${ }^{* *} \mathrm{P}<0.01,{ }^{* * *} \mathrm{P}<0.001$ as compared with the PBS/ OVA mice ( $\mathrm{n}=6-8 /$ group).

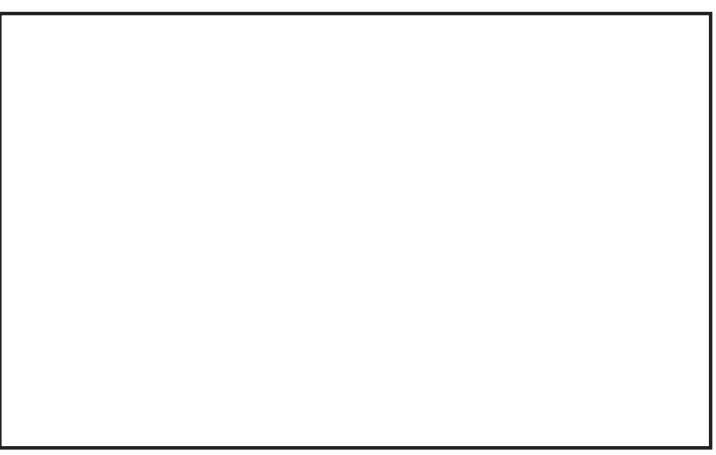

Fig. 7. Decreased expression of p-JAK2, p-STAT6 and reactive ROS, and increased FOXA2 mRNA in LPS pre-treated 16HBE cells. Western blotting of t-JAK2, t-STAT6, p-JAK2 and p-STAT6 protein expression in 16HBE cells (A). Expression of p-STAT6 mRNA in $16 \mathrm{HBE}$ cells as measured by q-PCR (B). Reactive ROS in $16 \mathrm{HBE}$ cells (C). Expression of FOXA2, AP-1 and NF$\kappa B$ mRNA in 16HBE cells as measured by q-PCR (D). Data are means $\pm \mathrm{SEM},{ }^{*} \mathrm{P}<0.05,{ }^{* *} \mathrm{P}<0.01,{ }^{* * *} \mathrm{P}<0.001$ as compared with the PBS/IL-13 cells.

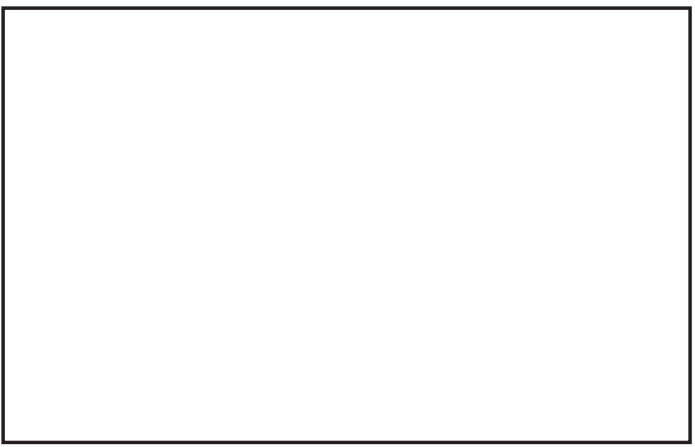

extracellular regulated protein kinases pathways (MAPK/ERK), Janus Kinase-Signal Transient and Activator of Transcription pathways (JAK-STAT) and the p38/MAPK pathway [12]. Therefore, western blotting analysis in vivo and in vitro were performed to investigate these signaling pathways. We detected that p-JAK2 and p-STAT6 were increased in OVAinduced mice (PBS/OVA) and IL-13 stimulated 16HBE cells (PBS/IL-13) compared with the control. However, LPS pre-treatment (LPS/OVA or LPS/IL-13) could significantly inhibit the IL-13-mediated p-JAK2 and p-STAT6 pathway (Fig. 6 A-B and Fig. 7 A-B, P<0.05) in vivo and in vitro.

In addition, ROS has been implicated in mucous hypersecretion in asthma and has been reported to be activated by IL-13 [13-15]. We also examined the level of ROS in vivo and in vitro. As shown in Fig. 6C and Fig. 7C, the generation of endogenous ROS was significantly elevated in the PBS/OVA mice and PBS/IL-13 cells compared with the control. After pretreatment with LPS (LPS/OVA or LPS/IL-13), ROS generation was significantly suppressed (Fig. 6C and Fig. 7C, P<0.05). Thus, reactive ROS in the OVA-induced asthma model was decreased following LPS pre-treatment, and this may be responsible for the decreased IL-13 production. This suggests that IL-13-induced oxidative stress may be ameliorated by LPS pre-treatment.

\section{Effect of LPS pre-treatment on the level of transcription factors}

To further detect the transcription factors involved in the expression of Muc5ac, we measured the in vivo and in vitro levels of FOXA2 mRNA, AP-1 mRNA, and NF- $\mathrm{kB}$ mRNA by q-PCR. We found that there was a significant decrease of FOXA2 mRNA (Fig. 6D and Fig. 7D, $\mathrm{P}<0.05$ ) in PBS/OVA mice and in PBS/IL-13 16HBE cells compared with the control group. LPS pre-treatment (LPS/OVA and LPS/IL-13) considerably increased the level of FOXA2 mRNA compared with the PBS/OVA mice and the PBS/IL-13 16HBE cells (Fig. 6D and Fig. $7 \mathrm{D}, \mathrm{P}<0.05)$. However, there was no difference in AP-1 mRNA and NF- $\kappa \mathrm{B}$ mRNA expression in vivo and in vitro. Therefore, FOXA2 expression, a transcriptional repressor of Muc5ac, was greatly increased after LPS pre-treatment and further down-regulated the Muc5ac gene transcription, thus reducing mucus production. 


\section{Discussion}

Mucous cell hyperplasia can be observed in the airways of almost every asthma patient and airway mucus plugging can affect the progression or aggravation in asthma or even lead to death [16]. However, there is no good treatment for mucus hypersecretion in asthma, thus specific drugs is required. Therefore, the mechanism of mucous hypersecretion needs to be explored. Inflammatory mediators produced in asthmatic airways can increase mucin secretion, induce plasma exudation, up-regulate muc5ac gene expression (muc5ac gene expression is thought to be a marker of goblet cell hyperplasia) [17], and cause goblet cell hyperplasia $[18,19]$. It's worth noting that IL-13, a cytokine released from Th2, is a major driver of asthma in a large subset of individuals, and appears to have a prominent role in MUC5AC expression and mucus production [3, 4, 20-22]. It has been reported that LPS exposure can down-regulate Th2 responses and thereby reduce cytokine IL-13 [8, 23]. Thus, in this study, we explored whether LPS pre-treatment could inhibit mucus hypersecretion and if so, what the underlying mechanisms of this effect were.

In our study, after pre-treatment with LPS before asthma was induced with OVA, the AHR, the peribronchial inflammation, the levels of IgE and IL-13, the goblet cell metaplasia as stained by PAS staining and the expression of Muc5ac in mice were significantly decreased, suggesting that LPS pre-treatment improved asthma by ameliorating AHR, peribronchial inflammation and mucous hypersecretion. In vitro, we used LPS pretreatment of IL-13stimulated 16HBE cells. The results of immunofluorescence and western blotting showed a significant decrease in Muc5ac in the cells. Therefore, our study demonstrated that pretreatment with LPS inhibited the IL-13-stimulated Muc5ac expression both in vivo and in vitro.

The JAK/STAT signaling pathway consists of the tyrosine kinase JAK family and the transcription factor STAT family, and is an important cytokine signal transduction pathway $[24,25]$. JAK is activated when IL-13 binds to the receptor IL-4R $\alpha$ or the IL-13R $\alpha 1$ chain, thereby activating the phosphorylation of STAT6 in the cytoplasm. STAT6 is a target protein downstream of the JAKs [24]. Studies have shown that the inflammatory mediators (especially IL-13) synthesized by Th2 cells are upstream stimulators for JAK/STAT6 pathway activation and can induce phosphorylation of STAT6. p-STAT6 is involved in goblet cell metaplasia and leads to excessive mucus secretion [26]. Therefore, the JAK/STAT6 pathway may play an important role in IL-13-induced airway hyper-reactivity and mucus over-production [27]. Thus, we studied the JAK/STAT6 signaling pathway. In our study, we found a significant increase of p-JAK expression in our OVA-induced asthma model, and LPS pre-treatment significantly decreased the levels of p-JAK. As such, we measured the change in STAT6 expression in each group. We found that p-STAT6 expression was significantly increased after OVA or IL-13 stimulation, and LPS pre-treatment inhibited the expression of p-STAT6. In addition, ROS plays an important role in mucus hypersecretion and airway inflammation, and ROS can activate the transcription factors which are sensitive to redox reactions [1, 28]. In addition, ROS is activated by IL-13, which in turn activates downstream signaling pathways. ROS not only activates STAT6 signaling pathways, but also activates STAT6 to stimulate more ROS production to form a positive feedback loop, resulting in substantial mucus secretion [13-15]. Our study also found that ROS levels were significantly increased with the activation of the STAT6 pathway, whereas LPS pretreatment inhibited the pathway activation and decreased ROS levels. The Muc5ac promoter contains FOXA2, AP-l, NF-кB and other transcription factor binding sites [29-31]. FOXA2 is a transcriptional repressor of Muc5ac and inhibits mucus hypersecretion [32], while AP-1 and NF- $\kappa$ B can promote transcription of the Muc5ac gene and increase hyperplasia in goblet cells [33-37]. Our results suggest that IL-13 can induce the expression of muc5ac expression, suggesting that FOXA2, AP-1 or NF- $\kappa$ B plays a role in muc5ac expression. The results of our q-PCR analysis showed that AP-1 and NF- $\mathrm{\kappa B}$ expression did not significantly change after IL-13 stimulation, whereas FOXA2 was decreased in our OVA-induced asthma model, and LPS pre-treatment significantly increased the levels. We hypothesized that increased IL-13 may stimulate the 


\section{Cellular Physiology Cell Physiol Biochem 2018:46:1263-1274 \begin{tabular}{l|l} 
DOI: 10.1159/000489109 & and Biochemistry \\
Published online: April 20, 2018 & $\begin{array}{l}\text { 2 } 2018 \text { The Author(s). Published by S. Karger AG, Basel } \\
\text { www.karger.com/cpb }\end{array}$
\end{tabular} \\ Ding et al.: LPS Protect Against Mucus Hypersecretion}

transcription and protein synthesis of MUC5AC by down-regulating FOXA2 expression, whereas LPS is effective in improving this process.

\section{Conclusion}

In summary, we are exposed to various concentrations of LPS in our daily life [38, 39]. Our results show that LPS pre-treatment can suppress IL-13-stimulated ROS generation and the JAK2/STAT6 pathway activation, and further promote transcription factor FOXA2, thus inhibiting Muc5ac expression and mucous hypersecretion in asthma (Fig. 8). Therefore, our results, combined with high-quality epidemiological finding, suggest that LPS preexposure in early life could reduce mucous hypersecretion, airway hyper-responsiveness and inflammation, and could thus protect against asthma [6-8].We speculate that in infants and young children, especially those with a family history of allergy, deliberate exposure to the endotoxin in the environment could reduce the risk of severe asthma. Furthermore, the above information could also be used to create therapeutic targets which, in turn, should lead to the rational design of anti-hypersecretory drugs

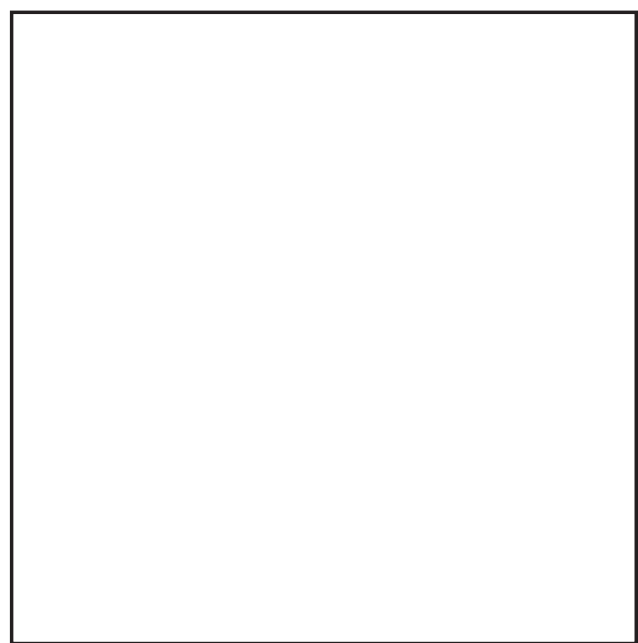

Fig. 8. Signaling pathways involved in IL13-mediated mucus synthesis. Binding of IL13 with IL-4R $\alpha$ or IL-13R $\alpha$ activates cytokine receptor-associated p-JAK2, resulting in increased p-STAT6. In addition, the increased ROS stimulated by IL-13 can also increase p-STAT6. Following dimerization, p-STAT6 translocates into the nucleus, and suppresses expression of FOXA2, a transcriptional repressor of Muc5ac. Together, these intracellular signaling events illustrate how IL-13 increases Muc5ac expression. for treatment of airway mucus hypersecretion in asthma. Thus, our study provides a basis for the creation of treatments for the prevention and treatment of asthma.

\section{Acknowledgements}

This work was supported by the Program for Innovative Research Team at Chongqing University, 2013.

\section{Disclosure Statement}

The authors have no conflicts of interest to declare.

\section{References}

1 Kim HJ, Park YD, Moon UY, Kim JH, Jeon JH, Lee JG, Bae YS, Yoon JH: The role of Nox4 in oxidative stressinduced MUC5AC overexpression in human airway epithelial cells. Am J Respir Cell Mol Biol 2008;39:598609.

- Hou L, Zhu L, Zhang M, Zhang X, Zhang G, Liu Z, Li Q, Zhou X: Participation of Antidiuretic Hormone (ADH) in Asthma Exacerbations Induced by Psychological Stress via PKA/PKC Signal Pathway in Airway-Related Vagal Preganglionic Neurons (AVPNs). Cell Physiol Biochem 2017;41:2230-2241. 


\section{Cellular Physiology Cell Physiol Biochem 2018;46:1263-1274 \begin{tabular}{l|l} 
and Biochemistry Published online: April 20, 2018 & $\begin{array}{l}\text { (c) } 2018 \text { The Author(s). Published by S. Karger AG, Basel } \\
\text { www.karger.com/cpb }\end{array}$
\end{tabular}}

Ding et al.: LPS Protect Against Mucus Hypersecretion

3 Kuperman DA, Huang X, Koth LL, Chang GH, Dolganov GM, Zhu Z, Elias JA, Sheppard D, Erle DJ: Direct effects of interleukin-13 on epithelial cells cause airway hyperreactivity and mucus overproduction in asthma. Nat Med 2002;8:885-889.

4 Ganesan S, Faris AN, Comstock AT, Chattoraj SS, Chattoraj A, Burgess JR, Curtis JL, Martinez FJ, Zick S, Hershenson MB, Sajjan US: Quercetin prevents progression of disease in elastase/LPS-exposed mice by negatively regulating MMP expression. Respir Res 2010;11:131.

5 Zhen G, Park SW, Nguyenvu LT, Rodriguez MW, Barbeau R, Paquet AC, Erle DJ: IL-13 and epidermal growth factor receptor have critical but distinct roles in epithelial cell mucin production. Am J Respir Cell Mol Biol 2007;36:244-253.

6 Schuijs MJ, Willart MA, Vergote K, Gras D, Deswarte K, Ege MJ, Madeira FB, Beyaert R, van Loo G, Bracher F, von ME, Chanez P, Lambrecht BN, Hammad H: Farm dust and endotoxin protect against allergy through A20 induction in lung epithelial cells. Science 2015;349:1106-1110.

7 Stein MM, Hrusch CL, Gozdz J, Igartua C, Pivniouk V, Murray SE, Ledford JG, Marques dSM, Anderson RL, Metwali N, Neilson JW, Maier RM, Gilbert JA, Holbreich M, Thorne PS, Martinez FD, von ME, Vercelli D, Ober C, Sperling AI: Innate Immunity and Asthma Risk in Amish and Hutterite Farm Children. N Engl J Med 2016;375:411-421.

8 Rigas D, Lewis G, Aron JL, Wang B, Banie H, Sankaranarayanan I, Galle-Treger L, Maazi H, Lo R, Freeman GJ, Sharpe AH, Soroosh P, Akbari O: Type 2 innate lymphoid cell suppression by regulatory T cells attenuates airway hyperreactivity and requires inducible T-cell costimulator-inducible T-cell costimulator ligand interaction. J Allergy Clin Immunol 2017;139:1468-1477.e2.

-9 Tian D, Fu Z, Liu E, He Y, Wang X, Wang L: Therapeutic effect of intratracheal administration of murine IL-4 receptor antagonist on asthmatic airway inflammation. J Asthma 2008;45:715-721.

10 Wang H, Joseph JA: Quantifying cellular oxidative stress by dichlorofluorescein assay using microplate reader. Free Radic Biol Med 1999;27:612-616.

-11 Tsuchiya K, Siddiqui S, Risse PA, Hirota N, Martin JG: The presence of LPS in OVA inhalations affects airway inflammation and AHR but not remodeling in a rodent model of asthma. Am J Physiol Lung Cell Mol Physiol 2012;303:L54-63.

12 Kelly-Welch AE, Hanson EM, Boothby MR, Keegan AD: Interleukin-4 and interleukin-13 signaling connections maps. Science 2003;300:1527-1528.

13 Hoshino A, Tsuji T, Matsuzaki J, Jinushi T, Ashino S, Teramura T, Chamoto K, Tanaka Y, Asakura Y, Sakurai T, Mita Y, Takaoka A, Nakaike S, Takeshima T, Ikeda H, Nishimura T: STAT6-mediated signaling in Th2dependent allergic asthma: critical role for the development of eosinophilia, airway hyper-responsiveness and mucus hypersecretion, distinct from its role in Th2 differentiation. Int Immunol 2004;16:1497-1505.

14 Hirakawa S, Saito R, Ohara H, Okuyama R, Aiba S: Dual oxidase 1 induced by Th2 cytokines promotes STAT6 phosphorylation via oxidative inactivation of protein tyrosine phosphatase 1B in human epidermal keratinocytes. J Immunol 2011;186:4762-4770.

15 Mandal D, Fu P, Levine AD: REDOX regulation of IL-13 signaling in intestinal epithelial cells: usage of alternate pathways mediates distinct gene expression patterns. Cell Signal 2010;22:1485-1494.

-16 DiGiovanni FA, Ellis R, Wattie J, Hirota JA, Southam DS, Inman MD: Concurrent dual allergen exposure and its effects on airway hyperresponsiveness, inflammation and remodeling in mice. Dis Model Mech 2009;2:275-282.

17 Takeyama K, Dabbagh K, Lee HM, Agustí C, Lausier JA, Ueki IF, Grattan KM, Nadel JA: Epidermal growth factor system regulates mucin production in airways. Proc Natl Acad Sci U S A 1999;96:3081-3086.

18 Jackson AD: Airway goblet-cell mucus secretion. Trends Pharmacol Sci 2001;22:39-45.

19 Rogers DF: Pharmacological regulation of the neuronal control of airway mucus secretion. Curr Opin Pharmacol 2002;2:249-255.

20 Oh CK, Geba GP, Molfino N: Investigational therapeutics targeting the IL-4/IL-13/STAT-6 pathway for the treatment of asthma. Eur Respir Rev 2010;19:46-54.

21 Woodruff PG, Modrek B, Choy DF, Jia G, Abbas AR, Ellwanger A, Koth LL, Arron JR, Fahy JV: T-helper type 2-driven inflammation defines major subphenotypes of asthma. Am J Respir Crit Care Med 2009;180:388395.

22 Kuperman DA, Huang X, Nguyenvu L, Hölscher C, Brombacher F, Erle DJ: IL-4 receptor signaling in Clara cells is required for allergen-induced mucus production. J Immunol 2005;175:3746-3752. 


\section{Cellular Physiology Cell Physiol Biochem 2018;46:1263-1274

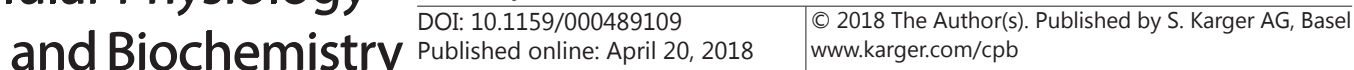 \\ Ding et al.: LPS Protect Against Mucus Hypersecretion}

23 Gereda JE, Leung DY, Thatayatikom A, Streib JE, Price MR, Klinnert MD, Liu AH: Relation between housedust endotoxin exposure, type $1 \mathrm{~T}$-cell development, and allergen sensitisation in infants at high risk of asthma. Lancet 2000;355:1680-1683.

24 Kiu H, Nicholson SE: Biology and significance of the JAK/STAT signalling pathways. Growth Factors 2012;30:88-106.

25 Schindler C, Darnell JE: Transcriptional responses to polypeptide ligands: the JAK-STAT pathway. Annu Rev Biochem 1995;64:621-651.

-26 O'Shea JJ, Plenge R: JAK and STAT signaling molecules in immunoregulation and immune-mediated disease. Immunity 2012;36:542-550.

-27 Perkins C, Yanase N, Smulian G, Gildea L, Orekov T, Potter C, Brombacher F, Aronow B, WillsKarp M, Finkelman FD: Selective stimulation of IL-4 receptor on smooth muscle induces airway hyperresponsiveness in mice. J Exp Med 2011;208:853-867.

-28 Nadeem A, Masood A, Siddiqui N: Oxidant--antioxidant imbalance in asthma: scientific evidence, epidemiological data and possible therapeutic options. Ther Adv Respir Dis 2008;2:215-235.

29 Li D, Gallup M, Fan N, Szymkowski DE, Basbaum CB: Cloning of the amino-terminal and 5'-flanking region of the human MUC5AC mucin gene and transcriptional up-regulation by bacterial exoproducts. J Biol Chem 1998;273:6812-6820.

-30 Song KS, Lee WJ, Chung KC, Koo JS, Yang EJ, Choi JY, Yoon JH: Interleukin-1 beta and tumor necrosis factoralpha induce MUC5AC overexpression through a mechanism involving ERK/p38 mitogen-activated protein kinases-MSK1-CREB activation in human airway epithelial cells. J Biol Chem 2003;278:23243-23250.

-31 Jonckheere N, Van Der Sluis M, Velghe A, Buisine MP, Sutmuller M, Ducourouble MP, Pigny P, Büller HA, Aubert JP, Einerhand AW, Van Seuningen I: Transcriptional activation of the murine Muc5ac mucin gene in epithelial cancer cells by TGF-beta/Smad4 signalling pathway is potentiated by Sp1 Biochem J 2004;377:797-808.

-32 Wan H, Kaestner KH, Ang SL, Ikegami M, Finkelman FD, Stahlman MT, Fulkerson PC, Rothenberg ME, Whitsett JA: Foxa2 regulates alveolarization and goblet cell hyperplasia. Development 2004;131:953-964.

-33 Ndengele MM, Muscoli C, Wang ZQ, Doyle TM, Matuschak GM, Salvemini D: Superoxide potentiates NFkappaB activation and modulates endotoxin-induced cytokine production in alveolar macrophages. Shock 2005;23:186-193.

34 Morcillo EJ, Cortijo J: Mucus and MUC in asthma. Curr Opin Pulm Med 2006;12:1-6.

-35 Lora JM, Zhang DM, Liao SM, Burwell T, King AM, Barker PA, Singh L, Keaveney M, Morgenstern J, GutiérrezRamos JC, Coyle AJ, Fraser CC: Tumor necrosis factor-alpha triggers mucus production in airway epithelium through an IkappaB kinase beta-dependent mechanism. J Biol Chem 2005;280:36510-36517.

-36 Poynter ME, Cloots R, van Woerkom T, Butnor KJ, Vacek P, Taatjes DJ, Irvin CG, Janssen-Heininger YM: NFkappa B activation in airways modulates allergic inflammation but not hyperresponsiveness. J Immunol 2004;173:7003-7009.

-37 Broide DH, Lawrence T, Doherty T, Cho JY, Miller M, McElwain K, McElwain S, Karin M: Allergen-induced peribronchial fibrosis and mucus production mediated by IkappaB kinase beta-dependent genes in airway epithelium. Proc Natl Acad Sci U S A 2005;102:17723-17728.

-38 Braun-Fahrländer C, Riedler J, Herz U, Eder W, Waser M, Grize L, Maisch S, Carr D, Gerlach F, Bufe A, Lauener RP, Schierl R, Renz H, Nowak D, von ME: Environmental exposure to endotoxin and its relation to asthma in school-age children. N Engl J Med 2002;347:869-877.

-39 Gehring U, Bischof W, Schlenvoigt G, Richter K, Fahlbusch B, Wichmann HE, Heinrich J: Exposure to house dust endotoxin and allergic sensitization in adults. Allergy 2004;59:946-952. 